\title{
Proliferation and Differentiation of Cultured MC3T3-E1 Osteoblasts on Surface- layer Modified Hydroxyapatite Ceramic with Acid and Heat Treatments
}

\author{
Tetsuya YUASA ${ }^{1}$, Youji MIYAMOTO ${ }^{2}$, Masayuki $\mathrm{KON}^{3}$, Kunio ISHIKAWA ${ }^{4}$, Masaaki TAKECHI ${ }^{1}$, Yukihiro \\ MOMOTA $^{1}$, Seiko TATEHARA ${ }^{1}$, Hideyuki TAKANO ${ }^{1}$, Shiho MIMAMIGUCHI ${ }^{1}$ and Masaru NAGAYAMA ${ }^{1}$ \\ ${ }^{1}$ Department of Oral and Maxillofacial Surgery, Institute of Health Biosciences, The University of Tokushima Graduate \\ School, 3-18-15, Kuramoto, Tokushima, 770-8504, Japan \\ ${ }^{2}$ Division of Dentistry and Oral Surgery, Akita University School of Medicine, 1-1-1, Hondou, Akita, 010-8543, Japan \\ ${ }^{3}$ Department of Biomaterials and Bioengineering, Institute of Health Biosciences, The University of Tokushima Graduate \\ School, 3-18-15, Kuramoto, Tokushima, 770-8504, Japan \\ ${ }^{4}$ Department of Biomaterials, Faculty of Dental Science, Kyushu University, 3-1-1, Maidashi, Higashi, Fukuoka 812-8582, \\ Japan \\ Corresponding author, E-mail:yuasa@dent.tokushima-u.ac.jp
}

Received February 14, 2005/Accepted March 31, 2005

\begin{abstract}
Effects of functionally gradient calcium phosphate consisting of hydroxyapatite (HAP) and $\alpha$-tricalcium phosphate ( $\alpha$-TCP) on proliferation and differentiation of osteoblasts were evaluated using MC3T3-E1 cells. There were no significant differences in the proliferation of MC3T3-E1 cells among HAP- $\alpha$-TCP functionally gradient calcium phosphate, pure HAP, and cell culture plastic wells. mRNA expressions of type I collagen, alkaline phosphate, and osteocalcine were evaluated as indexes of initial, mid-stage, and late-stage osteoblastic differentiation. Basically, HAP- $\alpha$-TCP functionally gradient calcium phosphate and pure HAP enhanced the expressions of the three markers when compared with that of cell culture plastic wells. For type I collagen and alkaline phosphate expressions, HAP- $\alpha$-TCP functionally gradient calcium phosphate showed the same expression level as pure HAP. For osteocalcine expression, HAP- $\alpha$-TCP functionally gradient calcium phosphate showed a higher level than pure HAP. We concluded, therefore, HAP- $\alpha$-TCP functionally gradient calcium phosphate has good potential to be a bone filler material with high osteoconductivity.
\end{abstract}

Key words: Osteoblasts, $\alpha$-tricalcium phosphate, Hydroxyapatite

\section{INTRODUCTION}

Since HAP shows excellent tissue response and good osteoconductivity $^{1-5)}$, much attention has been paid to developing hydroxyapatite (HAP: $\left.\mathrm{Ca}_{10}\left(\mathrm{PO}_{4}\right)_{6}(\mathrm{OH})_{2}\right)$ related materials with higher osteoconductivity. One of them is the so-called biphasic calcium phosphate $^{6-8)}$. In other words, combination of HAP and some other forms of calcium phosphate shows higher osteoconductivity than pure HAP. Combination of HAP and $\beta$-tricalcium phosphate $(\beta$-TCP: $\left.\beta-\mathrm{Ca}_{3}\left(\mathrm{PO}_{4}\right)_{2}\right)$ is the most typical biphasic calcium phosphate ${ }^{8)}$. Although, to date, the detailed mechanism for the high osteoconductivity of biphasic calcium phosphate is not yet clarified, at least two mechanisms have been widely accepted. One is the dissolution of the added calcium phosphate, leading to increase in calcium concentration. The increased calcium ion concentration then activates differentiation of osteoblasts. The other is caused by the dissolution-precipitation mechanism. In brief, added calcium phosphate dissolves to increase degree of supersaturation of the serum with respect to HAP, resulting in the precipitation of so-called bone-like apatite - whereby the resultant product contains a collageneous matrix. If these mechanisms are correct, calcium phosphates other than $\beta$-TCP should show a similar effect on enhancing osteoconductivity. On the other hand, $\alpha$-tricalcium phosphate $(\alpha$-TCP: $\left.\alpha-\mathrm{Ca}_{3}\left(\mathrm{PO}_{4}\right)_{2}\right)$ has the same composition as $\beta$-TCP but shows remarkably higher solubility than $\beta$-TCP. $\alpha$-TCP is used in dental and medical fields as a root sealer and bone-filling cement ${ }^{9-15)}$. In fact, $\alpha$-TCPHAP mixture was reported to bond with bone faster than HAP alone in vivo ${ }^{15)}$. It is claimed that the faster bone formation may be caused by the dissolution of $\alpha$-TCP around HAP. However, current biphasic calcium phosphate is a simple mixture of HAP and other calcium phosphate or a sintered product of HAP and other calcium phosphate.

Against the backdrop of the above-mentioned HAP combinations with other calcium phosphate, we proposed $\alpha$-TCP-HAP functionally gradient ceramic calcium phosphate in the present study. The surface was $\alpha$-TCP, but the content of $\alpha$-TCP gradually decreased with depth from the surface, such that the interior of the material was composed of pure HAP $^{6,7)}$. Basically, $\alpha$-TCP-HAP functionally gradient ceramic calcium phosphate was prepared based on chemical phase transformation and heat decomposition. In other words, HAP ceramics were exposed to acidic solution. HAP transformed to dicalcium phosphate dihydrate (DCPD: $\left.\mathrm{CaHPO}_{4} \cdot 2 \mathrm{H}_{2} \mathrm{O}\right)$ upon 
exposure to acidic solution since DCPD is more stable than HAP thermodynamically at acidic condition. DCPD and HAP reacted to form $\alpha$-TCP at the postsintering process, and the content of $\alpha$-TCP decreased with depth from the surface due to diffusion process. When $\alpha$-TCP-HAP functionally gradient ceramic calcium phosphate prepared in this way was immersed in simulated body fluid (SBF), the weight of the specimen initially decreased and then increased. On the other hand, HAP which was used as standard showed relatively the same weight. Although SBF evaluation is commonly employed as the initial screening test for osteoconductive materials, SBF evaluation reveals only chemical environmental information.

In the present investigation, therefore, effects of $\alpha$-TCP-HAP functionally gradient ceramic calcium phosphate on osteoblasts were studied in vitro, using HAP as control.

\section{MATERIALS AND METHODS}

Preparation of $\alpha$-TCP-HAP functionally gradient ceramic calcium phosphate

HAP ceramics used in this study were prepared as described in a previous study ${ }^{6}$. Briefly, HAP powder (Tomita Chemical, Tokushima, Japan) calcined at 700 ${ }^{\circ} \mathrm{C}$ for three hours was compacted into a disc-shaped mold under a pressure of $15 \mathrm{MPa}$. The obtained discs were heated up to $1200^{\circ} \mathrm{C}$ at a rate of $5^{\circ} \mathrm{C} / \mathrm{min}$, kept at $1200^{\circ} \mathrm{C}$ for two hours, and cooled in an electric furnace (Keramax BS4308N, Nikkato, Tokyo, Japan). Then, obtained HAP ceramics were supplied for the acid treatment. In the acid treatment, HAP ceramics were immersed in 1.0 or $5.0 \mathrm{~mol} / \mathrm{L}$ orthophosphoric acid $\left(\mathrm{H}_{3} \mathrm{PO}_{4}\right)$ for one hour. After immersion, the HAP specimens were rinsed with distilled water, and then ultrasonically washed in distilled water for 15 minutes. After acid treatment, specimens were heated to $1250^{\circ} \mathrm{C}$ at a heating rate of $5^{\circ} \mathrm{C} / \mathrm{min}$, then kept at $1250^{\circ} \mathrm{C}$ for one hour in a furnace under atmospheric condition. These obtained HAP discs were named $\operatorname{HAP}(1)$ and $\operatorname{HAP}(5)$ where number in the parenthesis denotes the concentration of the orthophosphoric acid used for the acid treatment. HAP $(0)$ indicates pure HAP that received neither acid nor heat treatment. HAP specimens thus obtained were $10 \mathrm{~mm}$ in diameter and approximately $1 \mathrm{~mm}$ in thickness.

\section{Cells and incubation condition}

In this study, MC3T3-E1 mouse osteoblast cells were used. The culture medium was an alpha-modified minimum essential medium (Dainihonseiyaku, Osaka, Japan) supplemented with $50 \mu \mathrm{g} / \mathrm{mL}$ ascorbic acid, 2 $\mathrm{mmol} / \mathrm{L} \quad \beta$-glycerophosphate (Sigma Chemical Co., St. Louis, MO, USA) and $10 \%$ fetal bovine serum (Whittaker Bioproducts Inc., Walkerville, MO, USA).
Each disc was placed in a plastic well (48 well cell culture cluster, Corning, NY, USA). Into each well was poured $500 \mu \mathrm{L}$ of the culture medium, and cell suspension was gently added to minimize the number of cells attaching to the side and undersurface of the disc, and the bottom of the well. Finally, MC3T3-E1 cells were seeded on each disc in concentration of 1 $\times 10^{3}$ cells per $10 \mathrm{~mm}$ disc per plastic well and incubated in atmosphere containing $5 \% \mathrm{CO}_{2}$ at $37^{\circ} \mathrm{C}$. Cell culture plastic wells were used as control.

\section{Proliferation of MC3T3-E1 cells}

Cell proliferation was measured at 2, 4, 6 days using MTT assay. MTT reagent (3-[4,5-dimetylthiazole-2yl]-2,5-diphenyltetrazolium bromide) was enzymatically converted by living cells into a blue/purple formazon product - which has been shown to be proportional to the number of living cells present. MTT reagent was added to each sample and incubated at $37^{\circ} \mathrm{C}$ for four hours. The blue formazon product was solubilized in dimethylsulfoxide, and the liquid of each sample removed for assay - which was performed in a 96-well plate. Absorbance was monitored on a microplate reader (MTP-32 Microplate Reader, Corona elect, Ibaragi, Japan) at $570 \mathrm{~nm}$.

\section{Differentiation of MC3T3-E1 cells}

To evaluate the differentiation of MC3T3-E1 cells, we measured the mRNA levels of type I collagen, alkaline phosphatase (ALP), and osteocalcin to quantify mineralization characteristics. Total RNAs were isolated from the cells using TRIzol (Gibco BRL, Rockville, MD, USA). Following which, reverse transcription-polymerase chain reaction (RT-PCR) analysis was performed. RNA samples were first treated with Deoxyribonuclease I (Gibco BRL) and converted into cDNA using random hexamer primers and reverse transcriptase (Gibco BRL). PCR was carried out using Reddy Mix PCR Master Mix (AB gene, Epsom, Surrey, UK). All primers were analyzed at Hokkaido System Science Co. Ltd. (Sapporo, Japan). PCR product sizes and primer sequences are summarized in Table 1. After RT-PCR, samples were electrophoresed on $2 \%$ agarose gel containing 100 $\mathrm{ng} / \mathrm{ml}$ ethidiumbromide. Band intensity was measured using NIH image software.

\section{Statistical analysis}

For statistical analysis, one-way factorial ANOVA and post hoc Fisher's PLSD test were performed using "Stat View 4.02" computer software (Abacus Concepts, Berkeley, CA, USA).

\section{RESULTS}

Fig. 1 shows the proliferation of MC3T3-E1 cells on the surfaces of $\operatorname{HAP}(0), \operatorname{HAP}(1), \operatorname{HAP}(5)$, and in the 
Table 1 Oligonucleotides used for PCR analysis

\begin{tabular}{clc}
\hline Gene of interest & \multicolumn{1}{c}{ Oligonucleotides } & Fragment size (bp) \\
\hline Type I collagen & $\begin{array}{l}\text { 5-TGACGAGACCAAGAACTG-3 } \\
\text { 5-CCATCCAAACCACTGAAACC-3 }\end{array}$ & \multirow{2}{*}{403} \\
\hline \multirow{2}{*}{ Alkaline phosphate } & $\begin{array}{l}\text { 5-ACGTGGCTAAGAATGTCATC-3 } \\
\text { 5-CTGGTAGGCGATGTCCTTA-3 }\end{array}$ & \multirow{2}{*}{475} \\
\hline \multirow{2}{*}{ Osteocalcin } & $\begin{array}{l}\text { 5-CATGAGAGCCCTCACA-3 } \\
\text { 5-AGAGCGACACCCTAGAC-3 }\end{array}$ & \multirow{2}{*}{310} \\
\hline \multirow{2}{*}{ G3PDH } & 5-ACCACAGTCCATGCCATCAC-3 & \multirow{2}{*}{ 5-TCCACCACCCTGTTGCTGTA-3 } \\
\hline
\end{tabular}

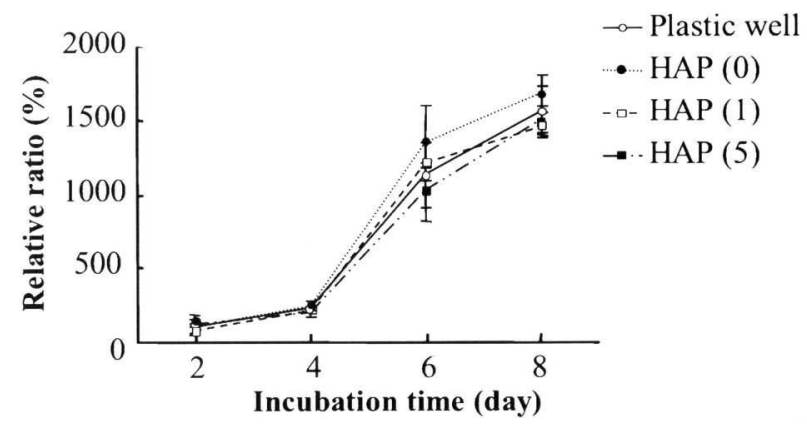

Fig. 1 The proliferation of MC3T3-E1 cells against incubation time. Each value was evaluated by an MTT assay and expressed as a percentage of the absorbance amount produced by the cells on plastic wells at Day 2. The results are shown as mean \pm standard deviation $(n=9)$. plastic wells. The number of osteoblasts on the surface of each sample increased with incubation time. No significant differences were observed between HAP and cell culture plastic wells or among the HAP groups except at Day 6 where $\operatorname{HAP}(1)$ and $\operatorname{HAP}(5)$ showed significantly lower values $(p<0.05)$.

Fig. 2 shows the amount of type I collagen mRNA used as an initial-stage differentiation index of MC3T3-E1 cells. Highest amount of type I collagen mRNA was observed at Day 6 regardless of specimen type. Basically, mRNA level of type I collagen was higher in HAP groups than that of plastic plate - except at Day 9 where no significant differences were observed between plastic plate and HAP groups. Further, at Day 9, type I collagen mRNA for $\operatorname{HAP}(1)$ was significantly lower than $\operatorname{HAP}(0)$

\section{3 day}

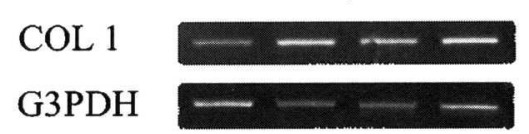

(a) (b) (c) (d)

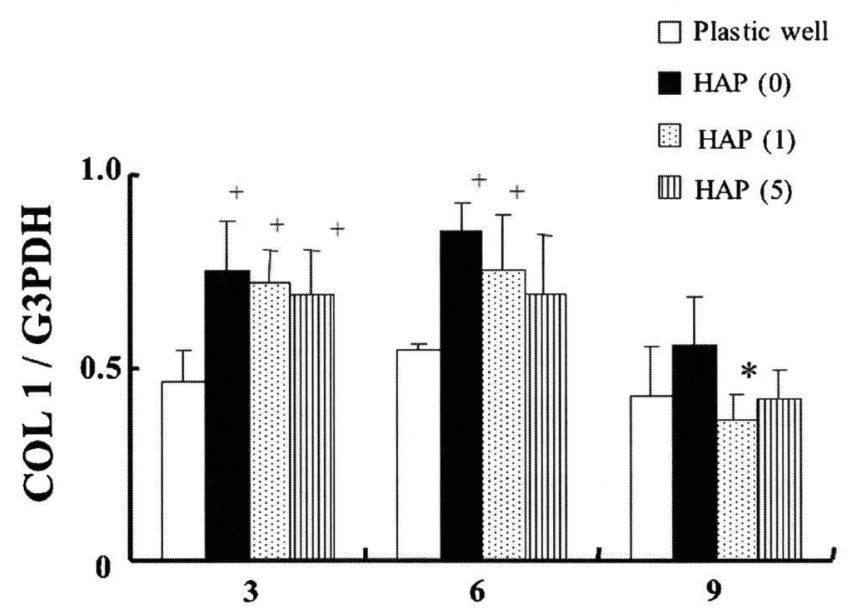

COL 1

6 day

G3PDH

(a) (b) (c) (d)

9 day

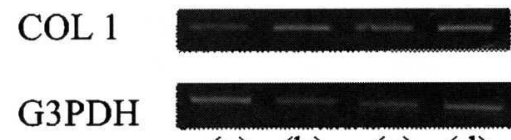

(a) (b) (c) (d)

(a) Plastic well

(b) HAP (0)

(c) HAP (1)

(d) HAP (5)

Incubation time (day)

Fig. 2 The mRNA expression levels of type I collagen of MC3T3-E1 cells against incubation time. The results are shown as mean \pm standard devision $(n=9)$. ${ }^{*}$ and ${ }^{+}$indicate a significant difference $(p<0.05)$ against $\operatorname{HAP}(0)$ and cell culture plastic well on the same day, respectively. COL 1: mRNA of type 1collagen. 


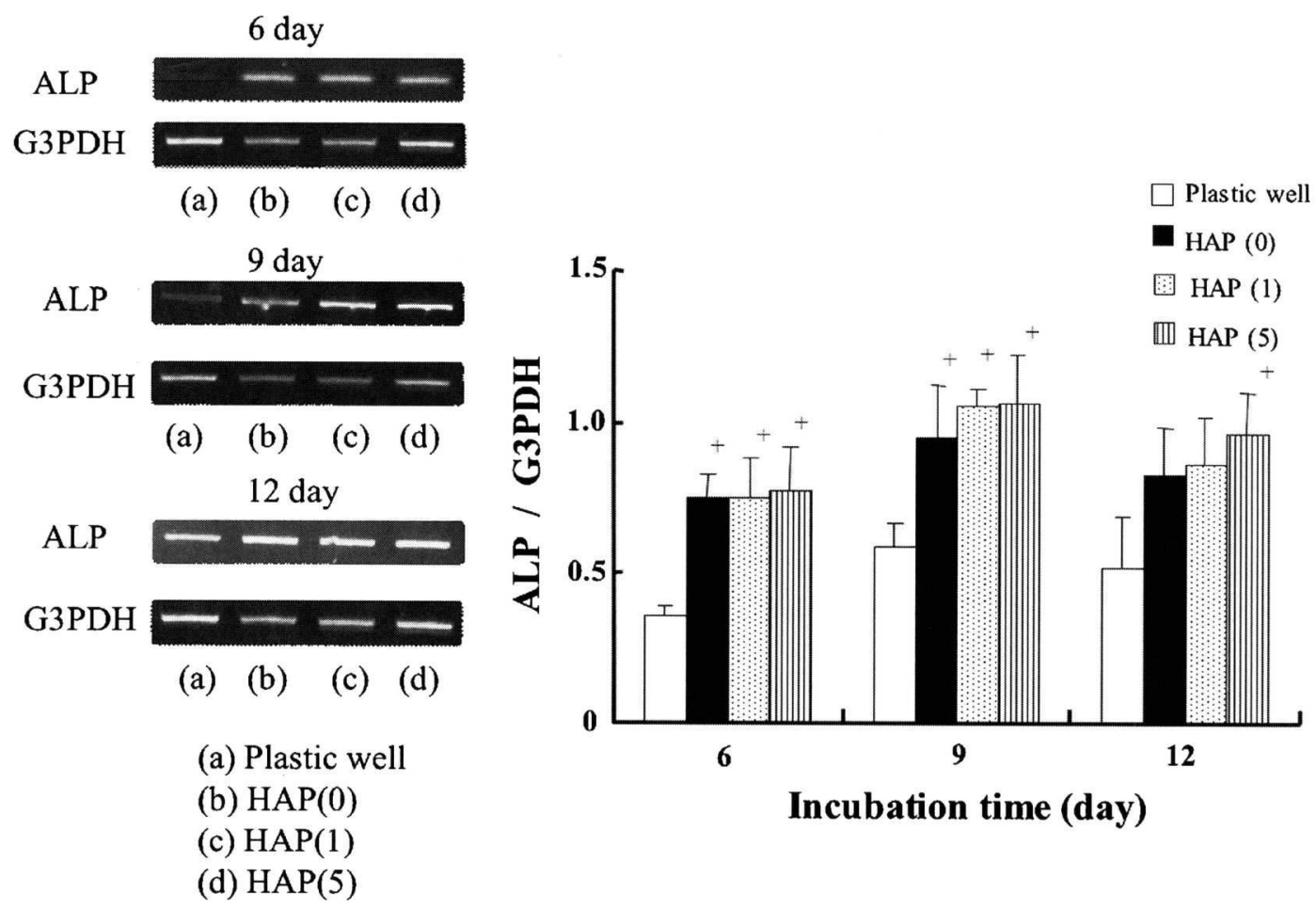

Fig. 3 The mRNA expression levels of ALP of MC3T3-E1 cells against incubation time. The results are shown as mean \pm standard deviation $(n=9) .{ }^{+}$indicates a significant difference $(\mathrm{p}<0.05)$ against cell culture plastic well on the same day. ALP: mRNA of ALP.

12 day

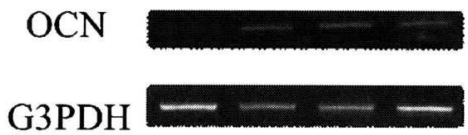

G3PDH (a) (b) (c) (d)

Plastic well

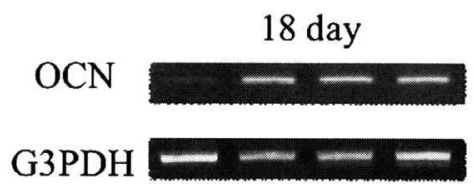

(a) (b) (c) (d)

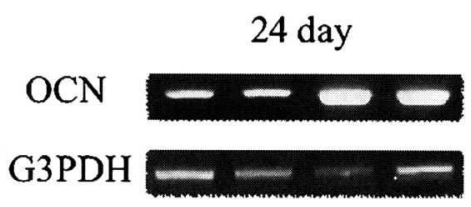

(a) (b) (c) (d)

(a) Plastic well

(b) HAP (0)

(c) HAP (1)

(d) HAP (5)

HAP (0)

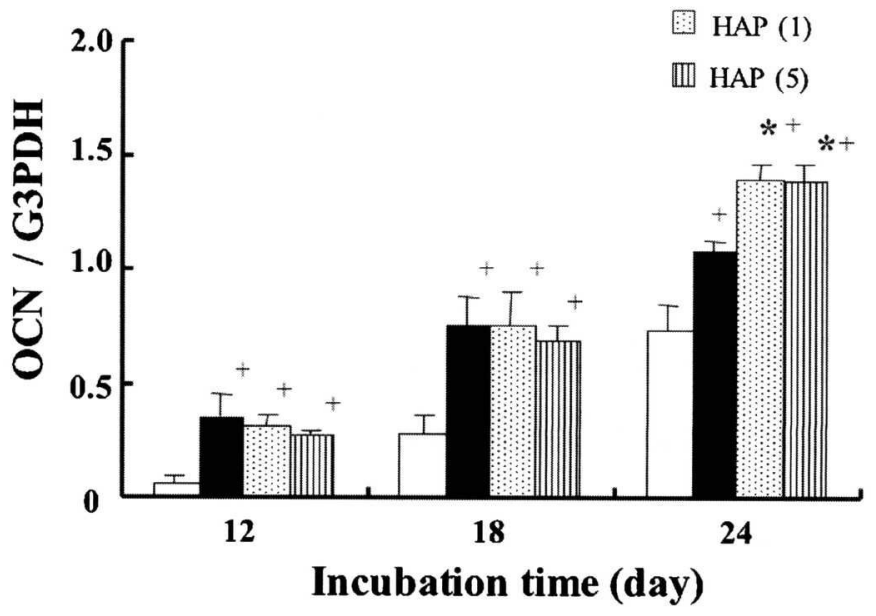

Fig. 4 The mRNA expression levels of osteocalcin of MC3T3-E1 cells against incubation time. The results are shown as mean \pm standard deviation $(n=9) .{ }^{*}$ and ${ }^{+}$indicate a significant difference $(p<0.05)$ against $\operatorname{HAP}(0)$ and cell culture plastic well on the same day, respectively. OCN: mRNA of osteocalcin. 
$(\mathrm{p}<0.05)$.

Fig. 3 shows the amount of ALP mRNA used as a mid-stage differentiation index of MC3T3-E1 cells. ALP mRNA levels on the surfaces of HAP groups were significantly higher than that of cell culture plastic well. No significant differences in ALP mRNA expression were observed among the types of HAP employed in the present investigation.

Fig. 4 shows the amount of osteocalcin mRNA used as a late-stage differentiation index of MC3T3E1 cells. The amount of osteocalcin mRNA increased with incubation time regardless of specimen type. When osteocalcin mRNA level was compared between HAP groups and cell culture plastic well, osteocalcin mRNA expression was higher in HAP groups than that of plastic well regardless of incubation period. At Days 12 and 18, no significant differences were observed among the HAP groups. However at Day 24, osteocalcin mRNA expressions on $\operatorname{HAP}(1)$ and HAP $(5)$ were significantly higher $(p<0.05)$ than that of $\operatorname{HAP}(0)$.

\section{DISCUSSION}

With respect to the proliferation of MC3T3-E1 cells, no differences were observed among the HAP types. This observation is consistent with a previous report on HAP- $\alpha$-TCP composite ${ }^{16)}$. Wang prepared a HAP$\alpha$-TCP composite by mixing HAP and $\alpha$-TCP in 70 : 30 and 35: 65 mass ratios and found no significant differences among the HAP types in osteoblastic proliferation ${ }^{16)}$. Although there was a big difference in terms of content and location of $\alpha$-TCP in HAP, observations in the present and previous studies demonstrated that HAP and $\alpha$-TCP had no differences in the ability of enhancing osteoblastic proliferation, or that the ability of enhancing osteoblastic proliferation was governed by HAP even when $\alpha$-TCP was contained in HAP. Similarly, no differences were observed between HAP groups and cell culture plastic dish with respect to the proliferation of MC3T3-E1 cells. Although some studies claimed that HAP promoted the proliferation of osteoblasts ${ }^{16,17)}$, most studies demonstrated that the proliferation profile of osteoblasts on HAP and cell culture dish were the same $^{18-20)}$. Indeed, the proliferation profiles of MC3T3-E1 cells on $\operatorname{HAP}(0), \operatorname{HAP}(1)$, and $\operatorname{HAP}(5)$ were the same with that of cell culture plastic well. It should be noted that having the same proliferation profile with cell culture plastic well is considered to be favorable. This is because cell attachment and proliferation profile on cell culture plastic well are known to be excellent when compared with other materials.

After proliferation stage, MC3T3-E1 cells need to be differentiated before mineralization. In the present study, we chose type I collagen, ALP, and osteocalcin as indexes of initial-, mid-, and late-stage differentiaion ${ }^{20)}$. When differentiation stage was compared between HAP and cell culture plastic well, MC3T3-E1 cells on HAP showed higher mRNA expression - except for type I collagen at Day 9 where no significant differences were observed between HAP and cell culture plastic well (Figs. 2-4). Type I collagen was the initial-stage index of osteoblastic differentiation. Therefore, no significant differences between HAP and cell culture plastic well at Day 9 did not mean that differentiation stage was the same between HAP and cell culture plastic well. Initial differentiation was over at Day 9 on HAP, and mRNA level of type I collagen at Day 9 was lower than that at Day 6 regardless of specimen type. Basically, the results obtained in the present study were consistent with the results reported previously ${ }^{18,19,21-24)}$. To date, the detailed mechanism of how HAP enhances osteoblastic differentiation has not been clarified. Nevertheless, protein adsorption kinetics and the effect of HAP on the structure of adsorbed proteins are reported to contribute to the enhancement of osteoblastic differentiation ${ }^{18,21,22)}$

When differentiation profiles were compared among HAP groups, it should be noted that higher expression levels of osteocalcin were observed on $\operatorname{HAP}(1)$ and $\operatorname{HAP}(5)$ than $\operatorname{HAP}(0)$ at Day 24. Osteocalcin was the late-stage differentiation marker, and is well known as typical bone formation marker. Therefore, higher expression of osteocalcin observed for MC3T3-E1 cells demonstrated clearly that HAP(1) and HAP(5) enhanced differentiation of MC3T3-E1 cells when compared with $\operatorname{HAP}(0)$. Interestingly, Ozawa et al. reported that they found significant increase in mRNA expressions of type I collagen and ALP when osteoblasts were cultured on HAP- $\alpha-\mathrm{TCP}^{19)}$. On the contrary, they found no significant differences between HAP and HAP- $\alpha$-TCP composite on osteocalcin. In this respect, results obtained by Ozawa et al. and those of the present study were in sharp contrast. If this difference were caused by a different preparation method and a different amount of $\alpha$-TCP in HAP, then the two preparation methods maybe combined to fabricate a HAP- $\alpha$-TCP composite that could peradventure promote an enhanced differentiation over a prolonged period of time.

In conclusion, we evaluated the effect of HAP$\alpha$-TCP functionally gradient materials on the proliferation and differentiation of cultured MC3T3-E1 osteoblasts and found that HAP- $\alpha$-TCP showed basically the same proliferation profile as pure HAP. However, an enhanced osteoblastic differentiation profile was observed at the late stage when compared with $\operatorname{HAP}(0)$. Based on the results of this cell study, further investigations are indeed required to clarify the behavior of osteoblasts on surfacemodified apatite. 


\section{ACKNOWLEDGEMENTS}

This work was supported in part by a Grant-in-aid for Scientific Research from the Ministry of Education, Culture, Sports, Science and Technology, Japan.

\section{REFERENCES}

1) Ito H, Wakisaka $Y$, Ohnuma $Y$, Koboki Y. A new porous hydroxyapatite ceramic prepared by cold isostatic pressing and sintering synthesized flaky powder. Dent Mater J 1994; 13: 25-35.

2) Kasai $T$, Ishikawa $K$, Suzuki $K$, Yatani H. Initial evaluation of a ceramic form as a reconstructive material for bone defect. Dent Mater J 2000; 19: 381-388.

3) Mimura K, Watanabe K, Okawa S, Kobayashi M, Miyakawa O. Morphological and chemical characterizations of the interface of a hydroxyapatite-coating implant. Dent Mater J 2004; 23: 353-360.

4) Sugawara A, Fujikawa K, Takagi S, Chow LC, Nishiyama M, Murai S. Histopathological and cell enzyme studies of calcium phosphate cements. Dent Mater J 2004; 23: 613-620.

5) Tieliewuhan Y, Hirata I, Sasaki A, Minagi H, Okazaki M. Osteoblast proliferation behavior and bone formation on and in $\mathrm{CO}_{3}$ apatite-collagen sponges with a porous hydroxyapatite frame. Dent Mater J 2004; 23: 258264.

6) Kon M, Hirakata LM, Miyamoto Y, Kawano F, Asaoka K. Surface-layer modification of hydroxyapatite ceramics with acid and heat treatments. Dent Mater J 2002; 21: 170-180.

7) Hirakata LM, Kon M, Asaoka K. Evaluation of apatite ceramics containing $\alpha$-tricalcium phosphate by immersion in simulated body fluid. Bio-Medical Materials and Engineering 2003; 13: 247-259.

8) Ioku $\mathrm{K}$, Yanagisawa $\mathrm{K}$, Yamasaki $\mathrm{N}$, Kurosawa $\mathrm{H}$, Shibuya K, Yokozeki H. Preparation and characterization of porous apatite ceramics coating with $\beta$ tricalcium phosphate. Bio-medical Materials and Engineering 1993; 3: 137-145.

9) Monma $\mathrm{H}$ and Kanazawa $\mathrm{T}$. The hydration of $\alpha$ tricalcium phosphate. J Ceram Soc Jpn 1976: 84(4): 209-213.

10) Nagse M, Chen RB, Asada $Y$, Nakajima T. Radiographic and microscopic evaluation of subperiosteally implanted blocks of hydrated and hardened $\alpha$ tricalcium phosphate in rabbit. J Oral Maxillofac Surg 1989; 47: 582-586.

11) Nagse $M$, Chen RB, Asada $Y$, Nakajima T. Evaluation of a bone substitute prepared from $\alpha$-tricalcium phosphate and an acid polysaccharide solution. J Oral Maxillofac Surg 1991; 49: 1305-1309.
12) Shiga $\mathrm{Y}$, Shimogoryo R, Oka $T$, Matsuya $S$, Ishikawa $\mathrm{K}$. The effects of initial hemostatic period on the mechanical strength and transformation of apatite cement. Dent Mater J 2004; 23(3): 335-339.

13) Tajima S, Nishimoto N, Kishi Y, Matsuya S, Ishikawa $K$. Effects of added sodium alginate on mechanical strength of apatite cement. Dent Mater J 2004; 23(3): 329-334.

14) Tanaka S, Kishi $T$, Shimogoryo R, Ishikawa K. Biopex acquires anti-washout properties by adding sodium alginate into its liquid phase. Dent Mater J 2003; $22(3)$ : 301-312.

15) Harada Y. Experimental studies of healing process on compound blocks of hydroxyapatite particles and tricalcium phosphate powder implantation in rabbit mandible. Journal of Tokyo Dental college Society 1989; 89: 263-297.

16) Wang C, Duan Y, Markovic B, Barvara J, Howlett $\mathrm{CR}$, Zhang $\mathrm{X}$, Zreiqat $\mathrm{H}$. Phenotype expression of bone-related genes in osteoblasts grown on calcium phosphate ceramics with different phase composition. J Biomed Mater Res 2004; 25: 2507-2514.

17) Iishima K, Sudo H, Yamamoto $S$. The behavior of MC3T3-E1 cells on synthetic hydroxyapatite surface. Tohoku Univ Dent J 1988; 15(1): 15-24.

18) Puleo DA, Holleran LA, Doremus RH, Bizios R. Osteoblast response to orthopedic implant materials in vitro. J Biomed Mater Res 1991; 25: 711-723.

19) Ozawa $S$ and Kasugai S. Evaluation of implant materials (hydroxyapatite, glass-ceramics, titanium) in rat bone marrow stromal cell culture. Biomaterials 1996; 17(1): 23-29.

20) Yuasa $T$, Miyamoto $Y$, Ishikawa $K$, Takechi $M$, Momota Y, Tatehara S, Nagayama M. Effect of apatite cements on proliferation and differentiation of human osteoblasts in vitro. Biomaterials 2004; 25: 11591166.

21) Hott M, Noel B, Bernache-Assolant D, Rey C, Marie PJ. Proliferation and differentiation of human trabecular osteoblastic cells on hydroxyapatite. J Biomed Mater Res 1997; 37: 508-516.

22) Zreiqat H, Evans P, Howlett CR. Effect of surface chemical modification of bioceramic on phenotype of human bone-derived cell. J Biomed Res 1999; 44: 389396.

23) Wilke A, Orth J, Lomb M, Fuhrmann R, Kienapfel H, Griss P, Franke RP. Biocompatibility analysis of different biomaterials in human bone marrow cell culture. J Biomed Res 1998; 40(2): 301-306.

24) Maxian SH, Stefano TD, Melican MC, Tiku ML, Zawadsky JP. Bone cell behavior on Matrigel-coated $\mathrm{Ca} / \mathrm{P}$ coating of varying crystallinities. $\mathrm{J}$ Biomed Mater Res 1998; 40(2): 171-179. 